\title{
Genetic Interaction Between Wnt7a and Lrp6 During Patterning of Dorsal and Posterior Structures of the Mouse Limb
}

\author{
Maja Adamska, ${ }^{\dagger}$ Allison C. Billi, Susannah Cheek, and Miriam H. Meisler*
}

Erratum received 1 June 2005

The original article to which this Erratum refers was published in Developmental Dynamics (2005) 233:368-372

In the published version of this article, Table 1 was printed incorrectly. Please find the correct version of Table 1 printed herein.

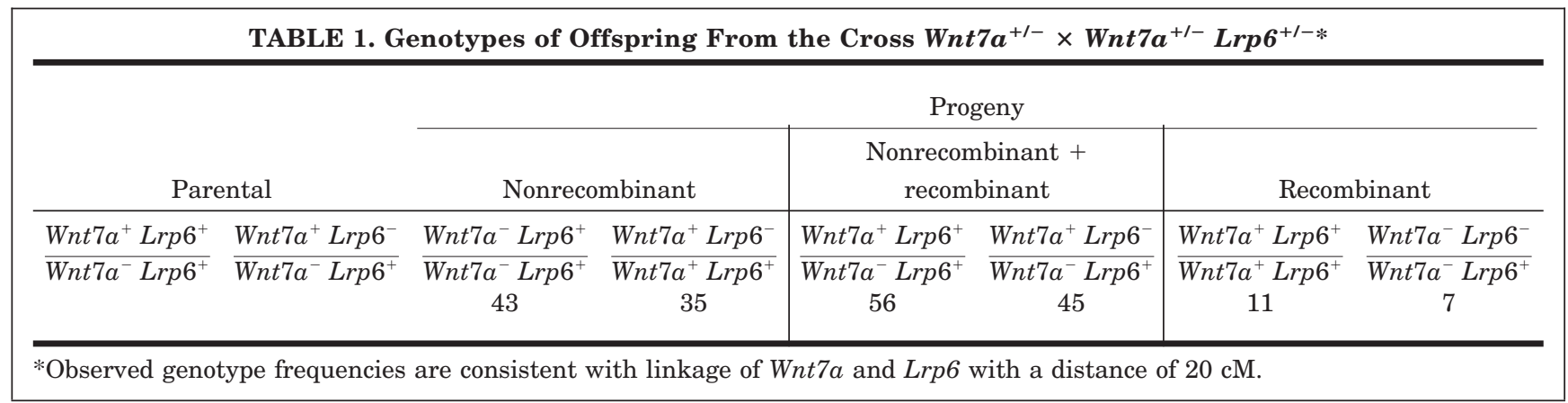

Department of Human Genetics, University of Michigan, Ann Arbor, Michigan Grant sponsor: NIH; Grant number: GM24872.

'Dr. Adamska's present address is School of Integrative Biology, University of Queensland, Brisbane, Qld 4072 Australia.

*Correspondence to: Miriam H. Meisler, Ph.D., Department of Human Genetics, University of Michigan, 4808 Medical Science II, 1241 E. Catherine Street, Ann Arbor, MI 48109-0618. E-mail: meislerm@umich.edu

DOI 10.1002/dvdy.20498

Published online 8 July 2005 in Wiley InterScience (www.interscience.wiley.com). 